\title{
Phase transitions in coated nickel titanium arch wires: A differential scanning calorimetric and $\mathrm{X}$-ray diffraction analysis
}

\author{
MANU KRISHNAN ${ }^{*}$, S SEEMA $^{\dagger}$, K SUKUMARAN ${ }^{\ddagger}$ and VASANT PAWAR ${ }^{* *}$ \\ Division of Orthodontics, Indian Army, 10 Corps Dental Unit, C/O 56 APO, Bathinda 151 001, India \\ ${ }^{\dagger}$ Department of Biochemistry, Jigme Dorje Wangchuk National Referral Hospital (JDWNRH), Thimphu, Bhutan \\ ${ }^{\ddagger}$ Materials Division, National Institute of Inter Disciplinary Science and Technology (NIIST) (CSIR), \\ Thiruvananthapuram 695 019, India \\ **Commandant and Classified Specialist (Orthodontics), Army Dental Centre (Research and Referral), Delhi Cantt, \\ Delhi 110010 , India
}

MS received 13 December 2011

\begin{abstract}
Shape memory and super-elastic properties of orthodontic nickel titanium wires, which are crucial for its clinical performance are dependent on the austenitic-martensitic phase transitions in its metallic microstructure that happen as a result of temperature or stress. The objective of this study was to compare the austenitic-martensitic phase transitions in new, black oxide coated nickel titanium (0.016 inch, Black Diamond, NiTi) arch wires in the 'as-received' form, from the manufacturer and 'retrieved form' after two months of intraoral use. This was done to analyse whether the new oxide coated nickel titanium wires suffered any significant loss in shape memory and super elasticity properties at the end of two months of intra oral use, findings of which could give valuable inferences prior to its widespread application in clinical practice.

Five arch wire samples in both groups were investigated for their austenitic-martensitic phase transitions in an in vitro set up, using differential scanning calorimetry (DSC), $\left(-90^{\circ}\right.$ to $100^{\circ} \mathrm{C}$ at a rate of $\left.10^{\circ} \mathrm{C} / \mathrm{min}\right)$ and $\mathrm{X}$-ray diffraction (XRD) analysis $\left(10^{\circ}\right.$ to $\left.90^{\circ}\right)$, as a function of temperature. Martensitic-austenitic thermograms showed an intermediate rhombohedral phase in the heating cycle of both groups, but cooling cycles showed direct reversal from austenitic to martensitic phase. Lower austenitic $\operatorname{start}\left(A_{\mathrm{S}}=10 \cdot 78 \pm 0.46^{\circ} \mathrm{C}\right)$ and finish $\left(A_{\mathrm{f}}=22 \cdot 26 \pm 0.24^{\circ} \mathrm{C}\right)$ temperatures of coated wires compared to the conventional wires showed (i) ability of the wire to remain in austenitic phase below oral temperature, that permits it to take up greater force during activation, (ii) increased springiness and (iii) consistent force delivery for an extended period of time. Statistical analysis with paired Student's ' $t$ ' test did not show any significant difference in mean values of transition temperatures and enthalpies between the two groups which proved similar shape memory and super-elastic properties at the end of intra oral use. Black oxide coating of NiTi wires may, therefore, be effective in diversified oral conditions and may find acceptable for re-use after sterilization. Low enthalpy values $(0 \cdot 92-3 \cdot 59 \mathrm{j} / \mathrm{g})$ compared to conventional ones, implied complete phase transition at the atomic level that can improve performance of the material in activation and deactivation cycles of NiTi wires. X-ray diffraction analysis of the two groups demonstrated predominance of austenitic phases $(A, 110$, 220 and 211) with complete reversibility at the atomic level. Discrete crystallographic structure and absence of multiple phases showed complete martensitic-austenitic transition, which authenticated the differential scanning calorimetric findings. This can earn acceptance for the new product in contemporary orthodontic practice with adequate scope for indigenization.
\end{abstract}

Keywords. Coated nickel titanium arch wire; austenitic-martensitic phase transition; differential scanning calorimetry; X-ray diffraction analysis.

\section{Introduction}

Nickel:titanium (NiTi) alloys in 50:50 proportions for orthodontic arch wires were introduced in 1971 by Andreason and Hilleman. The properties like shape memory and superelasticity of these wires have made them an indispensable material in contemporary orthodontic practice. These features are closely related to the phase transitions in its microstructure. NiTi alloys can exist in a high temperature,

\footnotetext{
*Author for correspondence (manukrishnanin@yahoo.co.in)
}

body centred cubic $(b c c)$, austenitic phase and low temperature, monoclinic, martensitic phase. This transition can occur as a function of temperature or stress. The first product of NiTi alloy orthodontic arch wire reported for clinical use was a martensitic stabilized alloy, without shape memory effect (Kusy and Wilson 1990). Later, in mid-eighties, Chinese and Japanese nickel titanium wires, with shape memory effect, were simultaneously introduced (Burstone et al 1985; Miura et al 1986). Commercial nickel titanium (NiTi) orthodontic arch wires presently used are generally classified into super-elastic and non-superelastic types 
(Khier et al 1991). The super-elastic wires are austenitic NiTi and the non-superelastic wires include martensitic stabilized structures. When the arch wire is placed into the brackets (loading), the active austenitic alloys undergo a reversible, stress induced transition to a martensitic version. Upon deactivation or unloading, the reverse phenomenon occurs, i.e. martensitic version is gradually converted into the austenitic phase. In fact, this transition is known as super-elasticity and it is the key attribute that works to resolve malocclusion in terms of levelling and alignment of teeth. Therefore, it follows that, evaluation of austenitic-martensitic phase transitions in NiTi wires can explain the super-elastic and shape memory features of NiTi arch wires.

However, it was later found that the phase transitions observed in several of the commercially marketed nickel titanium wires were not similar and simple as perceived (Leu et al 1990; Thayer et al 1993; Bradley et al 1996). They found that the transitions are complex with intermediate phases and related clinical effects. This is of paramount importance, because of its relationship with shape memory and super-elasticity. Moreover, thermal analysis done on nickel titanium endodontic files and orthodontic arch wires obtained after intra-oral use (retrieved samples) demonstrated considerable differences in the phase transitions from its unused versions (as-received samples) (Brantley et al 2002; Mallory et al 2003). It assumes greater significance considering the fact that the differences in phase transitions between 'as-received' and 'retrieved' nickel titanium arch wires can compromise its clinical efficiency (Bradley et al 2003; Brantley et al 2003). Therefore, it is imperative that shape memory and super elasticity properties of nickel titanium orthodontic arch wires assessed at the beginning of treatment should be similar to that at the end of treatment, to give consistent and desirable physical characteristics during the entire course of orthodontic treatment.

Coated nickel titanium arch wires are a new addition into the orthodontic inventory. In coating procedures, a substrate surface is usually refined by oxides, ethylene, teflon or with nitride ions to cause a permanent modification of the surface (Husmann et al 2002). Manufacturers of these new materials have been claiming better frictional features in sliding mechanics, enhanced esthetics, superior anti-corrosive properties and minimal nickel dissolution. However, the effect of such coatings, on the phase transitions of nickel titanium wires, which are very crucial for the clinical behaviour, has not been studied so far.

From the foregoing, it is evident that, conflicting findings already prevail regarding phase transitions in conventional nickel titanium wires. With the introduction of coated nickel titanium wires, it is, therefore, prudent to evaluate the phase transitions of 'as-received' and 'retrieved' samples; before they are put on routine clinical practice. This will explain whether the super-elastic and shape memory properties of the wire are retained after clinical use. Any significant difference in this aspect shall imply compromised clinical performance for the arch wire. It should be remembered that in a clinical situation, phase changes occur as a function of stress, but to evaluate the same in an experimental set up, thermal analysis is normally used. An in vitro calorimetric and X-ray diffraction study can, therefore, throw light on their phase transitions and probable differences in clinical behaviour.

The purpose of this study was, therefore, to investigate the phase transitions in the coated nickel titanium orthodontic arch wires in the 'as-received' form, from the manufacturer and 'retrieved' form, after intra oral use in patients, using differential scanning calorimetry (DSC) and X-ray diffraction (XRD) analysis and to determine whether any significant differences existed between the two, that can have valid clinical implications.

\section{Materials and methods}

\subsection{Sample design}

Black Diamond ${ }^{\mathrm{TM}}$ Nickel Titanium arch wire of Class One Orthodontics, St Lubbock TX, 79414, USA, was selected for the study. The product is available in different dimensions of $0.012,0 \cdot 014,0 \cdot 016,0.018$ and 0.020 inches. The present study was conducted with a 0.016 inch round arch wire, being the most popular dimension preferred for correcting malocclusion in the earlier stages of treatment. Reduced friction during sliding mechanics, improved resiliency, and excellent super-elastic properties are cited for this product by the manufacturer. The black oxide coating on the surface, a proprietary composition, is claimed to be an integral part of the wire and not a separate layer by them. The wire has a dimple centre mark, to ensure accurate placement during ligation and to prevent movement through the buccal tubes. Five arch wire samples in the standard blank forms, in their 'as-received' version, from the manufacturer and another five wire samples, after two months of intra-oral use, 'retrieved' from patients undergoing orthodontic treatment as shown in figure 1 were taken up for the study.

\subsection{Sample preparation}

$5 \mathrm{~mm}$ sections of the wire from premolar area of the arch wire were used as specimens for the analysis, because it is

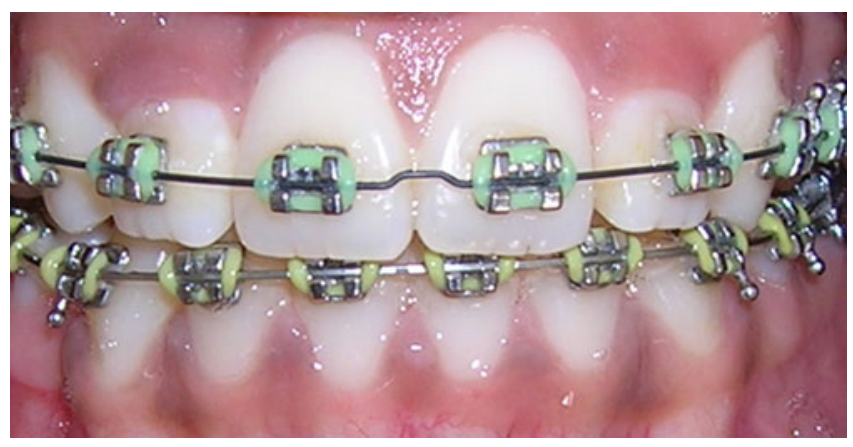

Figure 1. Black Diamond, coated nickel titanium wire along with conventional wire in intra-oral use. 
reported that those areas of the wire undergo less amount of stress, both in manufacture and during clinical use (Biermann et al 2007). The wire samples were cut with water cooled diamond saw; VC-50, Leco Corp, St Joseph, Mich, to prevent stress accumulation and heating, and was then weighed in an electronic balance. The samples were then placed in a non-hermetic aluminium crucible pan and sealed with a crimping instrument. An empty aluminium crucible served as reference for DSC analysis. Five segments of the wire were placed together to get good thermal contact within the sample and to display a DSC plot of adequate resolution.

\subsection{Differential scanning calorimetric and statistical analysis}

DSC analysis was done with a method based on ASTM E 1356-03 using DSC-Q 100 (Differential Scanning Calorimeter); TA instruments Inc. Fleming Centre, Crawley, and West Sussex. The samples were cooled from room temperature to $-90^{\circ} \mathrm{C}$ and then heated to $100^{\circ} \mathrm{C}$. The heating rate was $10^{\circ} \mathrm{C} / \mathrm{min}$. Subsequently, samples were again cooled to $-90^{\circ} \mathrm{C}$ in the same rate. The purge gas used was nitrogen of $99.99 \%$ purity, moisture $1 \mathrm{ppm}$, oxygen $1 \mathrm{ppm}$, at a purge rate of $50 \pm 5 \mathrm{ml} / \mathrm{min}$. The temperature axis was calibrated by indium melting method as per ASTM E 96703. In this analysis, heat flow to the sample and reference material, during the endothermic and exothermic cycles in a controlled scanning rate was displayed as a thermogram. The phase changes were determined from the tangent lines of DSC curve, when it deviated from the base line. The DSC manufacturer's software showed the DSC plots with heating onset and endset temperatures in degree celsius and heat enthalpy in joule/g for various phase transitions. Enthalpy changes for the phase changes were determined from the area under peak points with respect to the extrapolated base lines from adjacent parts of curve. The parameters of phase transitions in both the groups were statistically compared using paired Student's ' $t$ ' test with significance set at $p<0.05$.

\section{$2.4 \quad X$-ray diffractometry}

X-ray diffraction studies were performed with a Siemens D-5005 Powder Diffractometer with $\mathrm{Cu} K \alpha$ radiation of wavelength, $1.5418 \AA$, at $40 \mathrm{kV}$ and $30 \mathrm{~mA}$. The instrument had a diffracted beam monochrometer with $1^{\circ}$ divergent slit and $0.6 \mathrm{~mm}$ receiving slit. The instrument therefore, measured atomic spacing in crystals using diffraction of approximately monochromatic radiation. The instrument had two different modes of operation: A high resolution mode and high throughput mode. The former, usually used for single crystals with simple structure was used in the present study. Samples of the arch wires were mounted on clay, in a glass slide and diffraction measurements were done on a normal coupled scan. The scan started at an angle of $2 \theta: 10^{\circ}$ and ended at $2 \theta: 90^{\circ}$ with a step size of $0.1^{\circ}$ and count time of 0.6 s. Siemens software was used to plot XRD data. The $35-90^{\circ}$ area was closely scanned, as several significant peaks were found. The peaks on the plots were analysed and phases were subsequently identified by comparing XRD peaks with $d$-spacing given on JCPDS files (18-899) (Joint Commission on Powder Diffraction Standards, International Centre for Diffraction Data, Swarthmore, Pa).

\section{Results and discussion}

Figure 2 shows representative DSC plot for the 'as-received' coated nickel titanium wire samples. The plot displays the

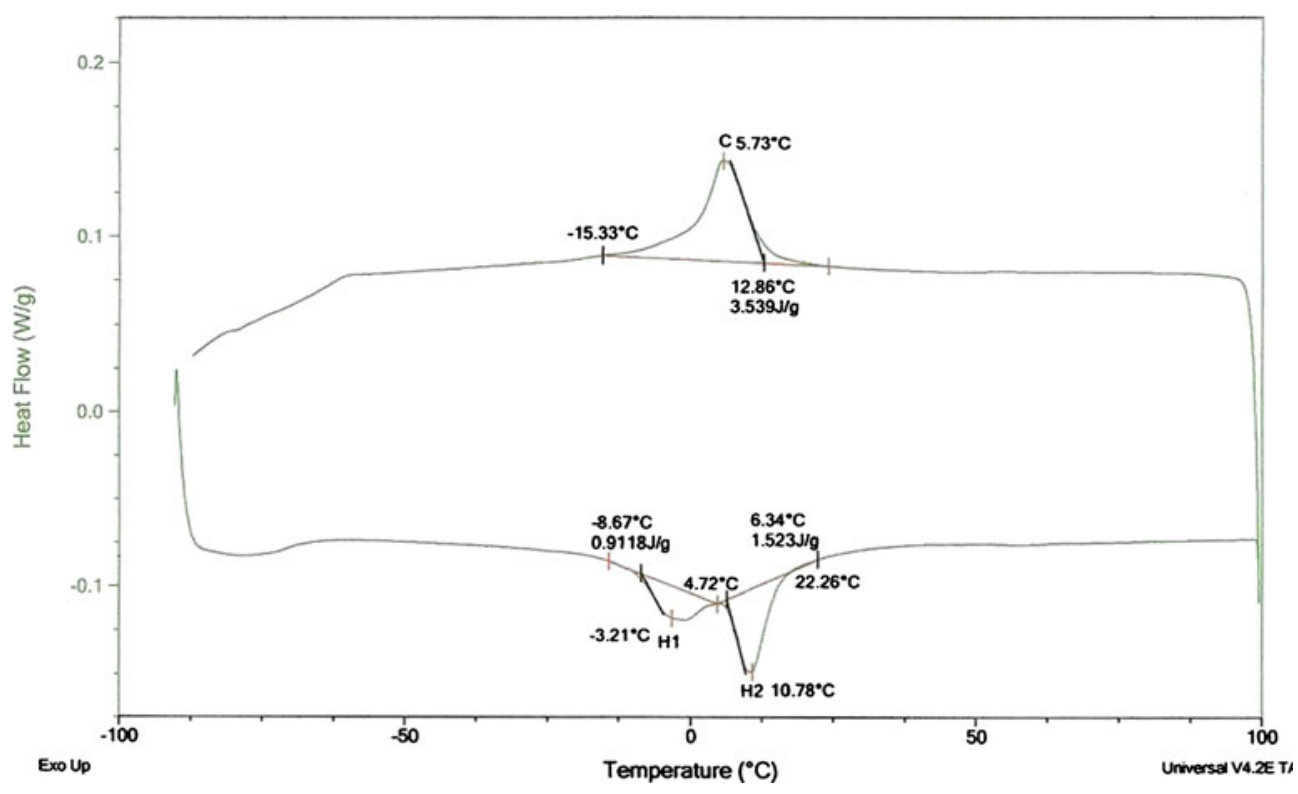

Figure 2. Representative differential scanning calorimetric plot for 'as-received' coated nickel titanium wire. 
heat flow to the samples vs temperature. The lower plot and peaks represented the heating curve and upper one indicated the cooling curve. In the heating phase of 'as-received' samples, two peaks were noticed viz. $H-1$ and $H-2$, which were related to the transition from martensitic to an intermediate rhombohedral $(R)$ phase and then to the austenitic phase. The mean values of the heating onset, maximum temperature, endset and heating enthalpy for this phase transition through the intermediate phase were thus determined. However, the cooling curve for the same samples showed only a single peak $(C)$ and was conspicuous with the absence of an intermediate $R$ phase that suggested a direct transition from austenitic to martensitic phase. Figure 3 shows repre- sentative DSC plot for the 'retrieved' coated nickel titanium wires after two months of intra oral use. The mean values of phase transitions in the heating phase and cooling cycle were also determined.

Observations were then tabulated in its mean and standard deviation as shown in table 1 . Phase transition parameters in the 'as-received' and 'retrieved' groups, when compared using paired Student's ' $t$ ' test at $p<0 \cdot 05$, did not show any significant difference, for majority of the mean values.

XRD scan of coated 'as-received' wire is shown in figure 4 and 5 representing XRD scan for 'retrieved' wire. The inter-planar spacing values of both the groups that related to lattice parameters like Miller indices, $h k l$ integers

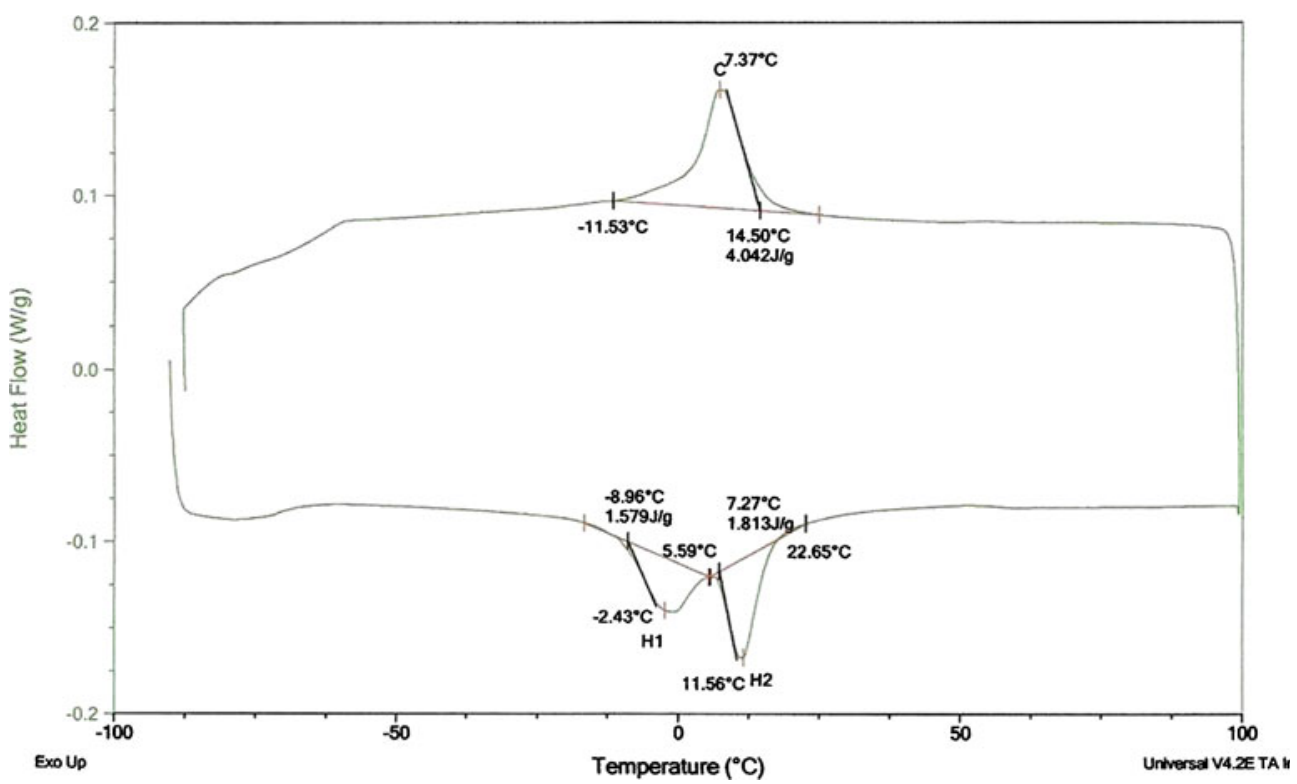

Figure 3. Representative differential scanning calorimetric plot for 'retrieved' coated nickel titanium wire.

Table 1. Comparison of temperature and enthalpy change between 'as-received' and 'retrieved' coated nickel titanium arch wires with differential scanning calorimetry.

\begin{tabular}{|c|c|c|c|c|c|}
\hline \multirow[b]{2}{*}{ Phase changes } & & 'As-received' C - NiTi & 'Retrieved' C - NiTi & $t$ value & $P$ value \\
\hline & & \multicolumn{4}{|c|}{ Heating cycle } \\
\hline \multirow[t]{4}{*}{ Martensite to $R$-phase } & Heating onset $\left({ }^{\circ} \mathrm{C}\right)$ & $-8.67 \pm 0.29$ & $-8.96 \pm 0.38$ & 1.887 & $>0.05$ \\
\hline & Peak $H-1\left({ }^{\circ} \mathrm{C}\right)$ & $-3.21 \pm 0.59$ & $-2.43 \pm 0.55$ & $-2 \cdot 163$ & $>0.05$ \\
\hline & Heating endset $\left({ }^{\circ} \mathrm{C}\right)$ & $4 \cdot 72 \pm 0 \cdot 36$ & $5.59 \pm 0.49$ & $-3 \cdot 199$ & $<0.05$ \\
\hline & Enthalpy change $(\mathrm{j} / \mathrm{g})$ & $0.92 \pm 0.33$ & $1.59 \pm 0.49$ & $-2 \cdot 216$ & $>0.05$ \\
\hline \multirow[t]{5}{*}{$R$-phase to austenite } & Heating onset $\left({ }^{\circ} \mathrm{C}\right)$ & $6 \cdot 34 \pm 0.67$ & $7 \cdot 27 \pm 0.59$ & $-2 \cdot 104$ & $>0.05$ \\
\hline & Peak $H-2\left({ }^{\circ} \mathrm{C}\right)$ & $10 \cdot 78 \pm 0.46$ & $11 \cdot 56 \pm 0.61$ & $-2 \cdot 182$ & $>0.05$ \\
\hline & Heating endset $\left({ }^{\circ} \mathrm{C}\right)$ & $22 \cdot 26 \pm 0 \cdot 24$ & $22.65 \pm 0.43$ & -1.771 & $>0.05$ \\
\hline & Enthalpy change $(\mathrm{j} / \mathrm{g})$ & $1.52 \pm 0.12$ & $1 \cdot 81 \pm 0 \cdot 21$ & -1.294 & $>0.05$ \\
\hline & & \multicolumn{4}{|c|}{ Cooling cycle } \\
\hline \multirow[t]{4}{*}{ Austenite to martensite } & Cooling onset $\left({ }^{\circ} \mathrm{C}\right)$ & $12 \cdot 86 \pm 0 \cdot 91$ & $14 \cdot 50 \pm 0 \cdot 99$ & $-2 \cdot 727$ & $<0.05$ \\
\hline & Peak $C\left({ }^{\circ} \mathrm{C}\right)$ & $5.73 \pm 0.98$ & $7 \cdot 37 \pm 0.96$ & $-2 \cdot 154$ & $>0.05$ \\
\hline & Cooling endset $\left({ }^{\circ} \mathrm{C}\right)$ & $-15.33 \pm 1.45$ & $-11.53 \pm 0.93$ & $-3 \cdot 206$ & $<0.05$ \\
\hline & Enthalpy change $(\mathrm{j} / \mathrm{g})$ & $3 \cdot 59 \pm 0.74$ & $4.042 \pm 0.65$ & $-2 \cdot 146$ & $>0.05$ \\
\hline
\end{tabular}


and JCPDS tables, used to determine the existing phases in the arch wire are displayed in table 2. The long (110) and short peaks $(220,211$ and 220) corresponded to the austenitic phases. The austenitic peaks predominated in the group of 'retrieved' wires also, along with few short peaks.

The super-elastic nature of NiTi wire is explained by the transition of austenitic to martensitic phase during loading and reversion to austenitic during unloading. This stress induced transition of austenitic to martensitic phase of NiTi alloys manifest as a flat plateau in the load deflection curve with no stress-strain correlation. It is also known that the super-elastic wires display a phenomenon of hysteresis, i.e. the force induced during activation (engagement of arch wire into the brackets) is not exactly reciprocated during deactivation (when wire undergoes stress induced phase transition, to bring teeth into alignment). Shape memory is a closely related phenomenon to super-elasticity, where a plastically deformed wire returns back to its originally fabricated shape, when heated above its transition temperature. This transition is reversible during clinical use because super-elastic alloys have a phase transition temperature lower than the mouth temperature. It is also established that the transition temperature of NiTi wires is affected by the composition, fabricating methods and relative proportions of the austenitic and martensitic forms in its microstructure (Kusy and Whitley 2007).

In the present study, phase transitions of coated nickel titanium arch wires were initially evaluated with a differential scanning calorimetry and were later confirmed with X-ray diffraction analysis. In the heating cycle, both the

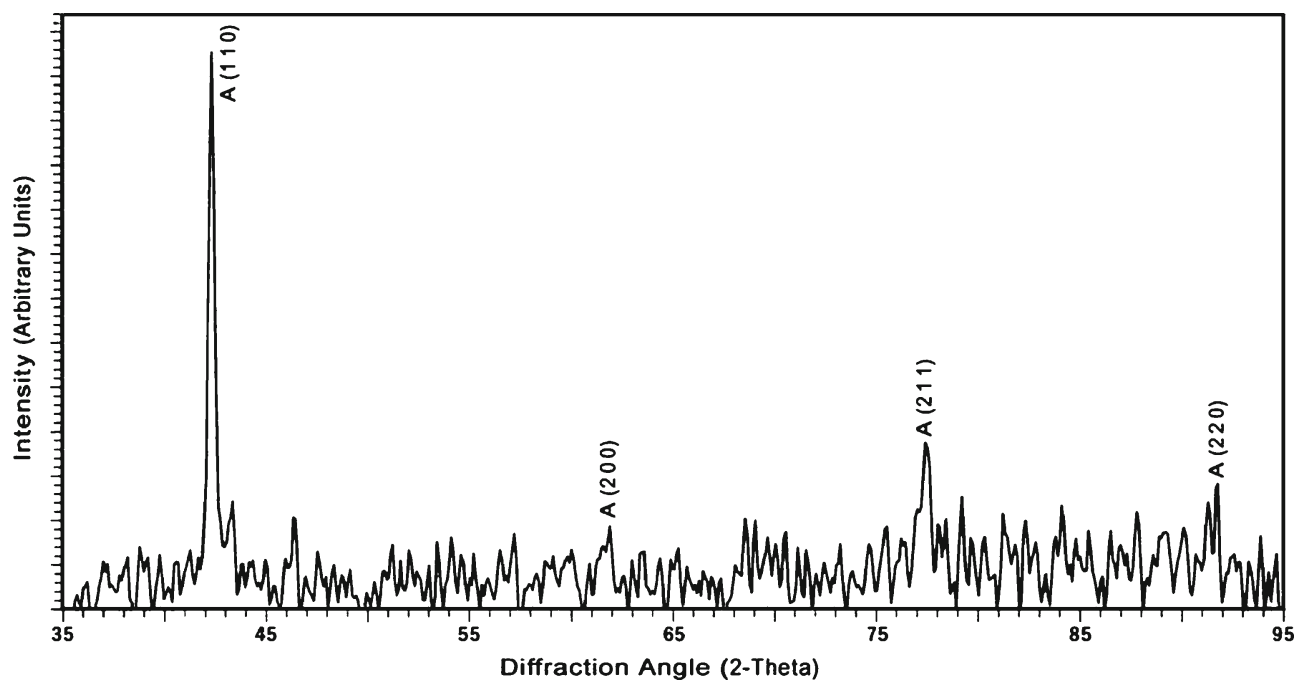

Figure 4. Representative X-ray diffraction scan for 'as-received' coated nickel titanium wire at $2 \theta$ : $35-95^{\circ}$ with major and minor peaks.

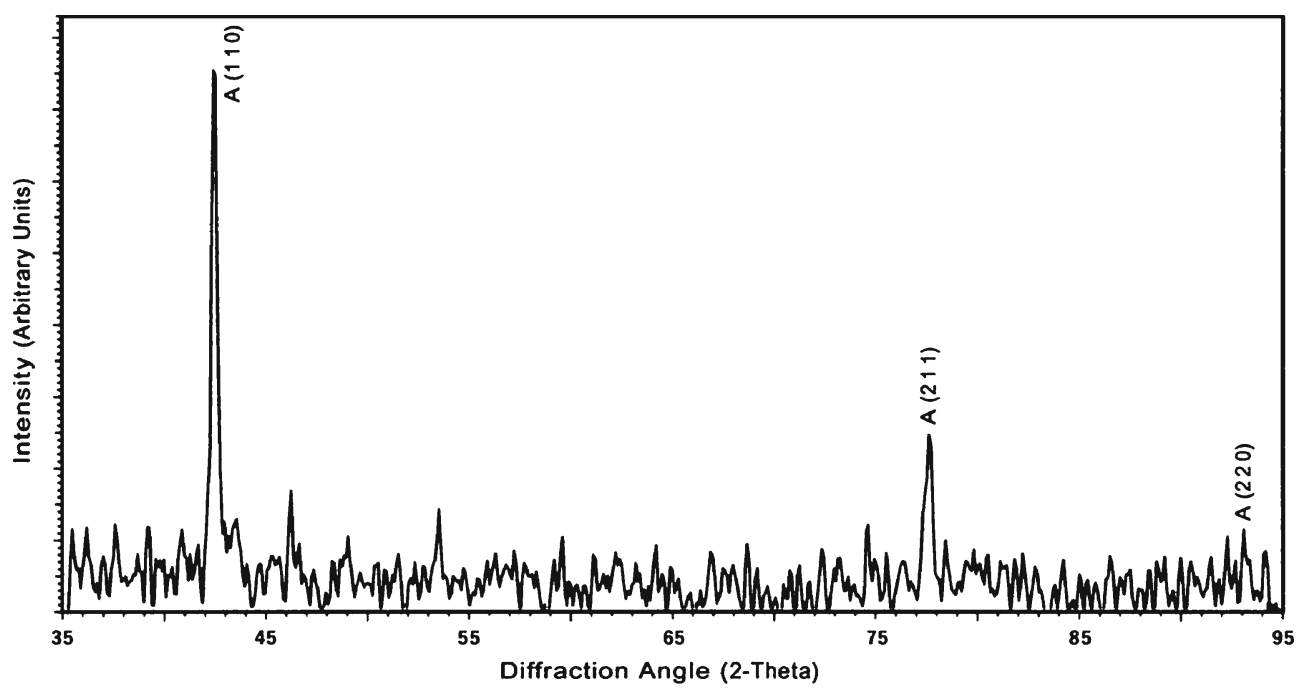

Figure 5. Representative X-ray diffraction scan for 'retrieved' coated nickel titanium wire at 20:35$95^{\circ}$ with major and minor peaks. 
Table 2. Lattice parameters for 'as-received' and 'retrieved' NiTi wires.

JCPDS files 18-899, Rad. $\mathrm{Cu} \mathrm{K} \alpha \lambda 1.54050$

\begin{tabular}{lrl}
\hline $\mathrm{d} A$ & $I / I_{1}$ & $h k l$ \\
\hline $2 \cdot 111$ & 100 & 110 \\
1.496 & 40 & 200 \\
1.222 & 60 & 211 \\
1.059 & 10 & 220 \\
\hline
\end{tabular}

'as-received' and 'retrieved' groups showed the presence of an intermediate rhombohedral $(R)$ phase, in the martensitic to austenitic transition. These phase changes are represented by the $H-1$ and $H-2$ peaks in the thermogram. This was in agreement with few of the results reported for conventional nickel titanium wires (Todoroki and Tamura 1987; Bradley et al 1996; Brantley et al 2002) but was not in tandem with certain other studies (Ijima et al 2002; FischerBrandis et al 2003). On the contrary, the cooling or exothermic phase demonstrated a direct austenitic to martensitic transition. Similar changes have been previously stated for super-elastic NiTi wires by some investigators (Ijima et al 2002; Fischer-Brandis et al 2003). However, Brantley et al (2003) observed the presence of an $R$ phase in the cooling cycle, using temperature modulated DSC. In a supporting claim, Todoroki and Tamura (1987) through electrical resistivity measurements showed an additional peak in the cooling cycle, but admitted that the resolution of electrical resistivity values were much lower than the DSC evaluation. The current mean values for the cooling cycle were similar to the findings of Leu et al (1990), even though there were differences in the cooling procedures. They had used dry ice in place of liquid nitrogen for cooling. There is a possibility that an intermediate $R$ phase may be present in small quantity in the cooling cycle that is difficult to estimate. It is important to note that, in the present investigation, phase transitions were determined after actual intra-oral use of the samples. This is because, it is logical to make inferences from studies conducted on arch wire samples subjected to real clinical use, which can incorporate all complex variables of stress, normally encountered in resolving malocclusion. The cooling cycle of coated NiTi wires did not show the presence of any intermediate phase in our evaluation. The differences in the material composition and the amount of 'cold working' induced during manufacture have been cited as the probable reasons for an intermediate phase in super-elastic NiTi wires (Fariabi et al 1989).

The mean values of austenitic start $\left(A_{\mathrm{s}}\right)$ and finish $\left(A_{\mathrm{f}}\right)$ temperatures of the 'as-received wires' were $10.78 \pm 0.46^{\circ} \mathrm{C}$ and $22.26 \pm 0.24^{\circ} \mathrm{C}$, respectively. Thus, a transition temperature, lower than the mouth temperature, was observed for the coated NiTi wires. The temperatures were lower than those reported for conventional nickel titanium wires (Bradley et al 1996; Ijima et al 2002; Biermann et al 2007), but were in close approximation to that stated by Chen et al
(1992). Some of the samples in previous studies included copper nickel titanium wires and wide range of NiTi alloys like super-elastic, non-superelastic and martensitic stabilized varieties. The present study was solely restricted to the coated super-elastic NiTi alloy arch wires and considering the homogeneity of samples, the narrow mean deviation observed was normal. The low $\left(A_{\mathrm{f}}\right)$ values noticed for the coated nickel titanium wires in this study may be significant clinically. It meant that, these wires remain austenitic well below oral temperature and can take up greater force to engage into teeth/brackets in severe malocclusion. This makes the wire much springier and consistent in force delivery for an extended period of time, which happens to be a desirable clinical feature. The phase transitions did not correspond to any statistically significant temperature variations between 'as-received' and 'retrieved' groups; except for the heating endset, cooling onset and cooling endset values. The importance of these variations has to be investigated in detail in future.

The mean values in enthalpy, noticed in our study (0.9118-1.523 j/g for 'as-received' and 1.579-1.813 j/g for 'retrieved' wires) were in good agreement with the results of a comprehensive study conducted by Yoneyama et al (1992) on seventeen commercial varieties of conventional NiTi arch wires. In addition, the enthalpy values of the two groups did not show any statistically significant difference in the forward and backward cycles. It suggested that the shape memory and super-elasticity properties of coated arch wire did not suffer any depreciation at the end of two months of intra oral use. The fact that, the 'retrieved' coated NiTi arch wire can maintain similar shape memory and superelastic characteristics, like 'as received' version, opens up new avenues in re-using this wire for further clinical use in different patients after standard sterilization procedures. This meant that, effects of oral environment factors as reported by Sakima et al (2006) like, temperature differences, interactions with electrolytes, proteins, fluorides, and associated corrosion factors may have less deleterious effects on the coated wires because of the protective black oxide coating. This is in agreement with the author's previous surface characterization studies on coated nickel titanium wires (Krishnan 2007).

Since the enthalpy values are considered as a reliable indicator of the phase transitions as proved by Brantley et al (2002), the performance of the 'as-received' and 'retrieved' groups of coated NiTi wires can be considered to be within normal limits. It was also noticed that in the present investigation, there was a substantial decrease in the enthalpy values reported by Bradley et al (1996) for the phase changes for coated NiTi wires, compared to the conventional counterparts. A low enthalpy value for phase change meant easier phase transition, which in turn suggested a completely reversible change at the atomic level that can lead to a better clinical performance during activation and deactivation. The lack of complete reversibility in phases for the conventional NiTi wire in its microstructure had been explained as a reason by Brantley et al (2003) for its occasional dismal clinical 
performance. The differences in the composition and manufacturing methods of the coated NiTi wires can be suggested as possible reasons for the decrease in the enthalpy values.

The study groups were subjected to an XRD analysis after the DSC evaluation to ascertain the existing phases. During phase transition, XRD peaks change in position and intensity. These changes are dependent on the percentage of austenitic transition that occurred and also to the resolution power of the diffractometer. The inter-planar spacing (d) data, obtained from the diffractometer and corresponding ' $h k l$ ' integers and percentage of intensity determined from the JCPDS files (e.g. $2 \cdot 111 \AA$-110) suggested of an increased prevalence of austenitic phases for both the 'as-received' and 'retrieved' groups (A-110, $A-220$ and $A$-211). The results were in conformity with the observations of Thayer et al (1995) on conventional NiTi wires. The crystallographic structure of coated NiTi wire was discrete and no multiple phases were seen. This correlated well with the low enthalpy values observed in the DSC test, which implied a complete reversibility of phases at the atomic level. The $\mathrm{X}$-ray diffractometer analysis thus authenticated the findings observed with the DSC analysis.

\section{Conclusions}

(I) Differential scanning calorimetric evaluation of the 'as-received' and 'retrieved' coated nickel titanium arch wires showed the presence of an intermediate rhombohedral phase in the heating cycle from its martensitic to austenitic transition.

(II) No intermediate phase was observed for both the groups in their cooling phase that suggested of a direct transition from austenitic to martensitic phase.

(III) Austenitic start $\left(A_{\mathrm{s}}\right)$ and finish $\left(A_{\mathrm{f}}\right)$ temperatures of the 'as-received' and 'retrieved' wires were considerably lower than the conventional nickel titanium wires. This meant that the coated nickel titanium arch wire can remain austenitic well below oral temperature that allows it to take up greater force during activation, making the wire much springier and consistent in force delivery.

(IV) The phase changes did not show any statistically significant difference in mean enthalpy values between the 'as-received' and 'retrieved' forms. It implied that the coated nickel titanium wires maintained similar shape memory and super-elasticity properties after two months of intra-oral use. This can help in re-using the arch wire in different patients after sterilization. The black oxide coating can thus become beneficial in diversified oral environment.

(V) Decreased enthalpy values observed for coated wires compared to conventional wires showed easier and complete phase transition at the atomic level and can be attributed to the differences in the composition and manufacturing methods of the coated nickel titanium wires. This can improve the clinical performance of the NiTi wires in its activation and deactivation cycles.

(VI) Both the 'as-received' and 'retrieved' wires demonstrated predominance of austenitic peaks in the X-ray diffractometry. Discrete crystallographic structure and absence of multiple phases showed complete martensiticaustenitic transition, which authenticated the differential scanning calorimetric findings.

(VII) The study proved that the coated nickel titanium arch wires can become a useful tool in modern day orthodontic practice. Proper understanding of its phase transitions will help clinicians to make their practice more scientific rather than empirical.

(VIII) There exists a strong possibility for developing indigenized versions of coated nickel titanium arch wires for orthodontic practice in India, comparing the high cost of imported versions.

\section{References}

Andreasen G F and Hilleman T B 1971 J. Am. Dent. Assoc. 821373

Biermann M C, Berzins D W and Bradley T G 2007 Angle Orthod. 77499

Bradley T G, Brantley W A and Culbertson B M 1996 Am. J. Orthod. Dentofac. Orthop. 109589

Bradley T G, Maslowski M J, Toth J M and Monaghan P 2003 J. Dent. Res. 821538

Brantley W A, Svec T A, Iijima M, Powers J M and Grentzer T H 2002 J. Endod. 28774

Brantley W A, Iijima M and Grentzer T H 2003 Am. J. Orthod. Dentofac. Orthop. 124387

Burstone C J, Qin B and Morton J Y 1985 Am. J. Orthod. 87445

Chen R, Zhi Y F and Arvystas M G 1992 Angle Orthod. 6259

Fariabi S, Thoma P E and Abujudom D N 1989 Proc. ICOMAT 56556

Fischer-Brandis H et al 2003 J. Orofac. Orthop. 6488

Husmann P, Bourauel C, Wessinger M and Jager A 2002 J. Orofac. Orthop. 3199

Ijima M, Ohno H H, Kawashima I, Endo K and Mizoguchi I 2002 Dent. Mater. 1888

Khier S E, Brantley W A and Fournelle R A 1991 Am. J. Orthod. Dentofac. Orthop. 99310

Krishnan M 2007 Proc. IUMRS-ICAM 2420

Kusy R P and Wilson T W 1990 Dent. Mater. 6228

Kusy R P and Whitley J Q 2007 Am. J. Orthod. Dentofac. Orthop. 131229

Leu L, Fournelle R, Brantley W and Ehlert T 1990 J. Dent. Res. 69313

Mallory D C et al 2003 J. Dent. Res. 821536

Miura F, Mogi M, Ohura Y and Hamanaka H 1986 Am. J. Orthod. Dentofac. Orthop. 901

Sakima M T, Dalstra M and Melsen B 2006 Eur. J. Orthod. 28282

Thayer T A, Bagby M D, Moore R N and De Angelis R J 1993 J. Dent. Res. 72139

Thayer T A, Bagby M D, Moore R N and De Angelis R J 1995 Am. J. Orthod. Dentofac. Orthop. 107604

Todoroki T and Tamura H 1987 Trans. Jpn. Inst. Metals 2883

Yoneyama T et al 1992 Dent. Mater. J. 111 